\title{
The Greek Vorlage of Gos. Thom. 12:2
}

In chapter 1, I have dealt with the "mixed signals" of saying 12. It is worth noting that the text of this saying appears to be problematic. Since the analysis of Gos. Thom. 12 plays an important role in my discussion of the date and compositional history of the Gospel of Thomas, it seems justified to give here a treatment of the problems related to the text of this saying.

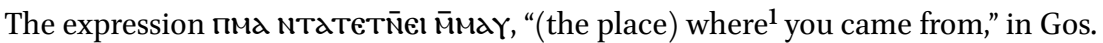
Thom. 12:2 is problematic. Quite remarkably, the Berliner Arbeitskreis offers two different interpretations of this phrase. In the first edition of their translation of the Gospel

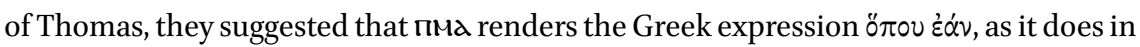
the Sahidic translation of Matt 8:19. According to their hypothesis, in the Greek Vorlage

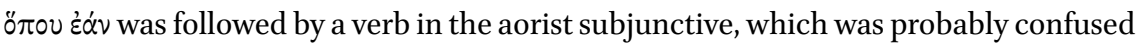
with the aorist in the indicative and thus rendered as the Coptic perfect. Assuming that $\bar{M} M a Y$ should be understood as $\mathbf{E M A Y}^{2}$, they suggested the following rendering of mMa

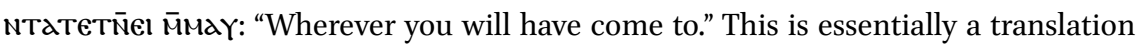

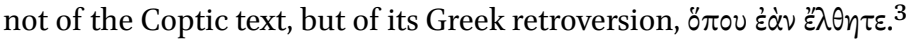

In the subsequent editions of the translation by the Berliner Arbeitskreis, this hypothesis was revised. According to their second, much more appealing, proposal, el M̄MaY in Gos. Thom. 12:2 stands in contrast to вळК ()d, "to go to," and thus should express the idea of "coming from." Indeed, there are reasons to suspect that $\bar{M} M a Y$ can

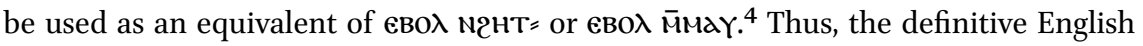
translation of Gos. Thom. 12 prepared by the Berliner Arbeitskreis (and slightly modified by Stephen J. Patterson and James M. Robinson) reads as follows: 5

12:1 The disciples said to Jesus: "We know that you will depart from us. Who (then) will rule over us?" 12:2 Jesus said to them: "(No matter) where you came from, you should go to James the Just for whose sake heaven and earth came into being."

1 For пma expanded by a relative clause constituting a subordinate "where"-clause, see Layton 2011, $429(\S 522)$.

2 It is worth noting that the substitution of emaY with $\bar{M} M a Y$ is a rare and late phenomenon; see Crum 1939, 197 .

3 See Bethge et al. 1996, 522; Plisch 1999, $5^{26}$.

4 See Plisch 1998, 77; Bethge 1998, 45.

5 Bethge et al. 2011, 3; cf. Bethge et al. 2005, 522. This understanding of the Coptic text of Gos. Thom. 12:2 was embraced in Nagel 2014, 113 . 
Yet the text of Gos. Thom. 12:2 remains problematic. In the Sahidic New Testament, пмג often renders an adverb of place: $0 ँ \pi \circ v, ~ \circ{ }^{0}, 0 \theta \varepsilon v$, etc. ${ }^{6}$ This is also the case with Gos. Thom. 30:1-2. Unfortunately, the Coptic text of this saying is extremely problematic, the Greek text preserved in P.Oxy. 1.1, 1l. 23-27 has suffered serious damage, and the relationship between the two is unclear, since there are several significant differences between the two texts. ${ }^{7}$ It is clear, however, that mma in Gos. Thom. $30: 1$ and $30: 2$ renders Greek ö $\pi \circ$.

It follows that חma in saying 12 likely corresponds to a Greek adverb of place. If, as the Berliner Arbeitskreis argues, $\bar{M}$ MaY in Gos. Thom. 12:2 is an equivalent of $€$ во $\lambda \bar{M} M a \gamma$, we

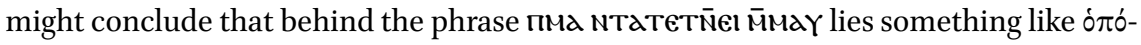
$\theta \varepsilon \nu \eta \eta \lambda \theta \varepsilon \tau \varepsilon$, "where you came from." This phrase, however, hardly makes good sense in the context of saying 12: note the parenthetical words the Berliner Arbeitskreis inserts into their translation in order to make the English text coherent.

It is tempting to suppose that the original Greek text of Gos. Thom. 12:2 meant something along the lines of what the Berliner Arbeitskreis has suggested; in this case we

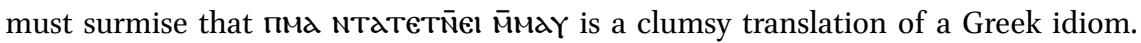
Which idiom could that be? Retranslating the Gospel of Thomas back into Greek is certainly an ungrateful task, yet in this particular instance, in order to make sense of Gos. Thom. 12:2, it is necessary at least to make an attempt to reconstruct the original Greek text and to propose a scenario that would explain the emergence of nMd NTdтеті̄єা M̄MaY.

The second retroversion suggested by the Berliner Arbeitskreis is $\pi \dot{0} \theta \varepsilon \nu$ है $\lambda \theta \eta \tau \varepsilon .{ }^{8}$ This retroversion is hardly plausible, since $\pi \dot{\theta} \theta \varepsilon v$ is an interrogative adverb. Moreover, the relative clause that employs the subjunctive mood usually requires the particle $\alpha^{\prime} \nu .^{9} \mathrm{I}$

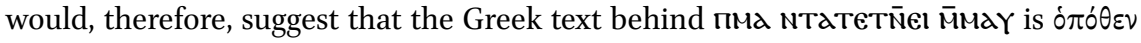

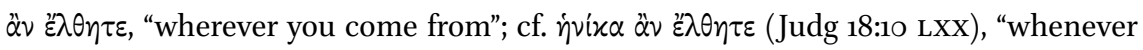

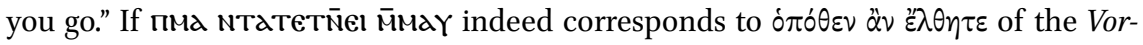
lage, then we may surmise that the Coptic translator struggled with the Greek syntax of Gos. Thom. 12:2 and came up with only an approximate translation.

To complete the picture, I suggest an alternative scenario: it is also possible that the Greek text available to the translator was corrupt and indeed read $\delta \pi \delta \theta \varepsilon v \eta \eta \lambda \theta \varepsilon \tau \varepsilon$, "where

6 See Wilmet 1957-1959, 1:314-324; cf. Crum 1939, 154b.

7 For an attempt to resolve some of the difficulties pertaining to this saying, see Attridge 1979; see also chapter 2 .

8 See Plisch 2008, 6o. Curiously enough, the retroversion of this phrase in Bethge et al. 2005,

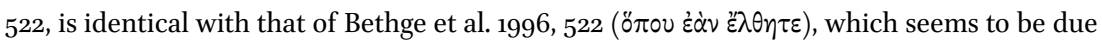
to an oversight.

9 See, e.g., Turner 1963, 107. 
you came from," instead of $\dot{\delta} \pi \dot{\theta} \theta \varepsilon \nu \grave{\alpha} \nu \varepsilon \grave{\varepsilon} \theta \eta \tau \varepsilon$. According to this scenario, at some point $\varepsilon^{2} \lambda \theta \eta \tau \varepsilon$ was confused with $\eta \hat{\eta} \lambda \theta \varepsilon \tau \varepsilon$, whereas $\alpha \dot{\alpha} \nu$ was omitted due to a homoeoteleuton.

While both of these scenarios start from unverifiable assumptions (i.e., either a somewhat incompetent scribe or a corrupt Greek manuscript), they at least shed some light on what could have brought about the phrasing of Gos. Thom. 12:2. I propose,

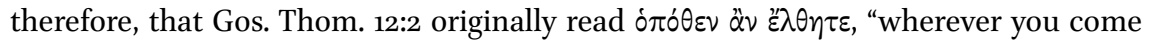
from," which agrees with the basic premise of the second translation proposed by the

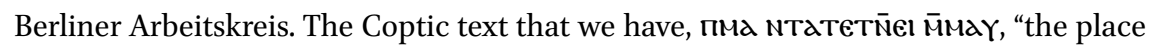
where you came from," is either a clumsy translation of the original reading, or an accu-

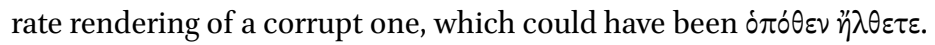

